\title{
Rodeo docs hope to lasso recognition
}

Rodeo health professionals want their brand of medicine recognized, say organizers of the first international rodeo medicine conference.

About 70 rodeo physicians $\exists$ and other health care professionals from across Western North America gathered in Calgary July 7-8, ahead of the city's Stampede, to share ideas on the treatment and prevention of ○ rodeo-related injuries. Organiz-

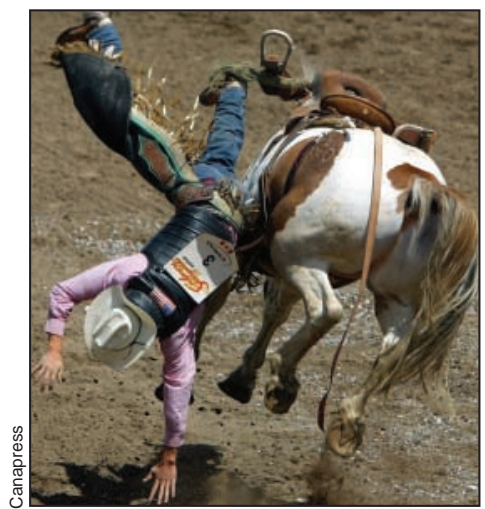

Ride 'em: Research is needed on how to prevent injury. ers hope the

boys to ride bulls after suffering a head injury. They would also like to build a force platform to measure real-time data on bull stomping and other causes of injury. This data can be used to design protective gear.

Few studies have been done on the unique injuries suffered during rodeos. These injuries range from sprained ankles to ruptured tendons, as cowboys tangle with animals exerting completely different forces than humans on a playing field.

"A football player might get collaborative research to make the most of limited funding.

Attendees developed a consensus on how to manage concussions, which they hope will be adopted by rodeo associations. One of the recommendations concerns not allowing cowtackled, but that's not the same as being stomped by a 2000pound bull," orthopedic surgeon Dr. Laurie Hiemstra says, from Calgary.

Hiemstra, a professor at the University of Calgary Sport Medicine Centre, was roped into volunteering with the Canadian Pro Rodeo Sports Medicine Team 3 years ago.

"These guys are the toughest athletes I've ever met," Hiemstra says. "If they come in and complain about something, you can bet they're in agony."

There are 35 members on the Canadian team, including certified athletic therapists, massage therapists, chiropractors and sports medicine physicians, many with experience in orthopedics. Members of the team attend the 19 largest professional rodeo events.

Team president Dale Butterwick, a senior instructor at the University of Calgary Sport Medicine Centre, led a landmark 5-year analysis of professional rodeo injuries (American fournal of Sports Medicine 2002;3[2]:1938). The analysis found that the worst events were bull riding (32.2 injuries per 1000 rides) and bareback riding (24.5 injuries per $1000)$. About $30 \%$ of the injuries were serious, including fractures, ruptures, dislocations and concussions.

Concussions accounted for $8.6 \%$ of all reported injuries; higher than previously reported. - Dina O'Meara, Calgary

INFECTIOUS DISEASE

\section{SARS vaccine undergoing animal testing}

Canadian researchers have developed 2 potential SARS vaccines now undergoing animal testing.

Both prototypes have produced antibody responses in animals, a first step toward the eventual development of a human vaccine, said Dr. Lorne Babiuk, director of the University of Saskatchewan's Vaccine and Infectious Disease Organization (VIDO). But it isn't known yet whether the antibodies will effectively block the I replication of the SARS virus, $\exists$ Babiuk said.

One of the prototypes is a conventional killed-virus vac㝏 cine developed by researchers at the BC Centre for Disease Con$\exists$ trol, the University of BC and VIDO.
The second vaccine was developed by researchers at McMaster University using an adenovirus vector, a common-cold virus that has been engineered with DNA from the SARS virus. The vaccines were tested on mice and ferrets at the Southern Research Institute in Alabama, a Level 3 laboratory.

"Both showed early signs of being able to provide protection" in animals, said Jack Gauldie, director of the Centre for Gene Therapeutics at McMaster. While the vaccine candidates have generated immunity, some aspects of the immunity may be damaging, he cautioned. Further tests on other animal models are likely, he said.

A human SARS vaccine could be available in about 2 years, depending on the final test results and whether "the disease rears its ugly head again," Babiuk added. Another outbreak would likely spur researchers to fast-track the process, he said.

Several other SARS vaccine candidates are currently under development in Canada, but all are in earlier test phases, Gauldie said. Canadian researchers began work on a vaccine just over a year ago, after an outbreak of the potentially deadly respiratory disease. Developing a market-ready vaccine usually takes about 10 years, but researchers are hoping to reduce the time substantially in the case of SARS. - Rosanna Tamburri, Oakville, Ont. 